\title{
Model experiments on large tabular iceberg evolution: ablation and strain thinning
}

\author{
Daniela JANSEN, Henner SANDHÄGER, Wolfgang RACK \\ Alfred Wegener Institute for Polar and Marine Research, PO Box 120161, D-27515 Bremerhaven, Germany \\ E-mail:djansen@awi-bremerhaven.de
}

\begin{abstract}
Antarctic tabular icebergs are important active components of the ice-ocean system. To investigate the relevance of inherent ice dynamics to iceberg evolution, we developed a numerical model based on the fundamental equations of ice-shelf flow and heat transfer, forced by environmental parameters of the ice-ocean-atmosphere system. Model experiments with idealized icebergs of constant density show that the strain thinning rate for a typical iceberg with a thickness of $250 \mathrm{~m}$ and a temperature of $-15^{\circ} \mathrm{C}$ is about $1 \mathrm{ma}^{-1}$. Sensitivity studies for different scenarios of environmental conditions confirmed the reliability of our model. A 5 year simulation of the evolution of iceberg A-38B yielded a mean decrease in thickness from $220 \mathrm{~m}$ to $106.3 \mathrm{~m}, 95 \%$ of which was caused by basal melting, $1 \%$ by surface melting and $4 \%$ by strain thinning. We found iceberg spreading decelerating by about $75 \%$, and ice temperatures being strongly affected by progressive erosion of the relatively warm basal layers and warming in the uppermost part. According to the model results, basal melting is the primary cause of change of iceberg geometry during drift, whereas strain thinning is only relevant in cold areas where basal melting is low.
\end{abstract}

\section{INTRODUCTION}

Large tabular icebergs calved from ice shelves at the periphery of Antarctica are remarkable glacial features of the Earth's southern polar region. Covering thousands of square kilometers, being several hundred meters thick and deteriorating progressively during their drift in the Southern Ocean, they represent active components of the ice-sheetice-shelf-ocean system. The oceanographic relevance of such icebergs consists, above all, in their potential to supply comparatively cold fresh water successively to the ocean during disintegration (Gladstone and others, 2001). This process influences the stability of the water column and thus affects water mass formation. Furthermore, grounding of large icebergs on shallow continental shelves and associated perturbations in the local bathymetric settings can cause changes in the circulation and affect sea-ice conditions (Nøst and Østerhus, 1998; Grosfeld and others, 2001). The particular role of icebergs within the glacial system is evident from the fact that calving at the ice fronts represents the main loss of mass from the Antarctic ice sheet. According to Jacobs and others (1992), iceberg calving $\left(\sim 2000 \mathrm{Gta}^{-1}\right)$ together with melting at the base of ice shelves $\left(\sim 550 \mathrm{Gta}^{-1}\right)$ exceeds the total annual mass gain of about $2200 \mathrm{Gt}$ due to snow accumulation. However, the calving rate of large icebergs is subject to substantial fluctuations, since it may take the ice shelf decades to readvance to its previous seaward extension after a major calving event.

Considering the typical life cycle of a large tabular iceberg from calving to final decay, the different factors governing iceberg evolution can be roughly divided into three classes. The first includes the various driving forces, which are exerted by ocean currents, wind stress and sea-ice pressure on the iceberg surfaces, and which cause icebergs to drift. Based on the force balance for iceberg motion in ice-covered seas, Lichey and Hellmer (2001) successfully simulated the drift trajectory of the large Antarctic iceberg C-7. Direct tracking and monitoring of large icebergs are usually done by analyzing satellite image sequences gathered with various sensors (e.g. Ballantyne, 2002).

The second class becomes apparent in a more-or-less continuous change of iceberg geometry during drift. Of primary importance are mass-exchange processes which are part of the iceberg-ocean and iceberg-atmosphere interactions. These processes are basal melting, surface accumulation or melting, and ice-front ablation due to wave erosion, melting, and calving of overhanging slabs. The rate of volume reduction is expected to increase significantly when icebergs approach lower latitudes, because the rise in ambient temperature leads to increased melting and reinforced decay of the iceberg margins. A further process contributing to continuous iceberg deformation is the strain thinning associated with ice-shelf-like spreading of the iceberg. To quantify this spreading, which is driven by the stress imbalance at the ice front and gradients in the icethickness distribution, the velocity of ice flow, the temperature regime and the iceberg geometry need to be known in detail. However, neither respective measurements nor specific model studies on the interrelation between inherent iceberg dynamics and climatic boundary conditions are yet available.

The third class of processes relevant to iceberg evolution is fracturing on various scales. Collisions with the ice-shelf front or other icebergs as well as grounding can induce bending moments in the iceberg which initiate crack formation and propagation. Fracture processes can also result from unbalanced hydrostatic stresses due to rapid inhomogeneous iceberg ablation. This might also explain the typical occurrence of small-scale calving at ice fronts with local melt enhancement. Knowledge of both the decisive mechanisms of iceberg fracturing and the possible links to the inherent stress distribution is still incomplete.

Since major fracture events usually occur in early and rather late states of large iceberg evolution, there are 

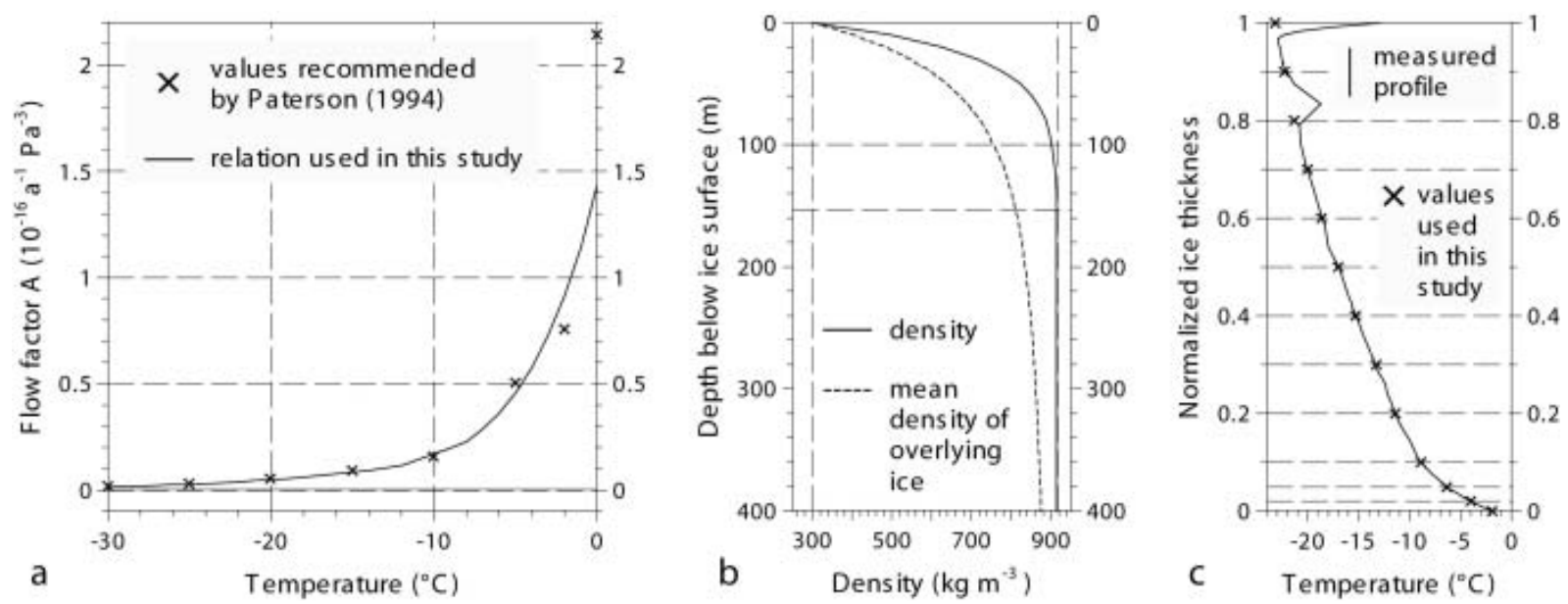

Fig. 1. (a) Temperature dependency of factor $A$ of Glen's flow law; (b) prescribed depth profiles of ice density $\rho$ and mean density of overlying ice $\bar{\rho}$; (c) temperature-depth profile based on borehole measurements near the Ronne Ice Shelf front (ice thickness at drill site was $240 \mathrm{~m}$ ). Marked temperature values were used to initialize time-dependent iceberg simulations.

comparatively long periods when changes in iceberg geometry mainly result from the processes of the abovementioned second class, i.e. strain thinning and continuous iceberg interaction with ocean and atmosphere. To gain deeper insight into this aspect of iceberg evolution, we have developed a numerical iceberg model and performed a series of basic and advanced simulations. After the model description in the next section, selected results from our experiments are presented, including a time-dependent simulation describing the substantial mass loss of the tabular iceberg A-38B during its 5 year drift from the Ronne Ice Shelf front to near South Georgia located $\sim 2500 \mathrm{~km}$ further north.

\section{MODEL DESCRIPTION}

The first version of the new tabular iceberg model simulates the continuous iceberg evolution caused by inherent ice dynamics and variable environmental boundary conditions. Driving forces and stresses associated with this class of influencing factors are implemented, but friction and vertical shear strain due to bending forces are neglected. Thus, the ice body is assumed to be in hydrostatic equilibrium with depth-invariant horizontal flow velocities. However, iceberg temperature and density are allowed to vary with depth. Considering this so-called ice-shelf approximation, the continuum-mechanical balance equations for momentum and mass, in combination with Glen's flow law, yield three model equations for the flow regime of tabular icebergs and ice shelves (e.g. MacAyeal and others, 1986). With regard to a regular Cartesian $x, y, z-$ coordinate system, these governing equations of iceberg flow read:

$$
\begin{aligned}
& 2 \frac{\partial}{\partial x}\left(F \dot{\varepsilon}_{x x}\right)+\frac{\partial}{\partial x}\left(F \dot{\varepsilon}_{y y}\right)+\frac{\partial}{\partial y}\left(F \dot{\varepsilon}_{x y}\right) \\
& =\bar{\rho} g H \frac{\partial(h-H)}{\partial x}+g \frac{\partial}{\partial x}\left(\int_{h-H}^{h} \int_{z}^{h} \rho \mathrm{d} z^{\prime} \mathrm{d} z^{\prime \prime}\right) \\
& 2 \frac{\partial}{\partial y}\left(F \dot{\varepsilon}_{y y}\right)+\frac{\partial}{\partial y}\left(F \dot{\varepsilon}_{x x}\right)+\frac{\partial}{\partial x}\left(F \dot{\varepsilon}_{x y}\right) \\
& =\bar{\rho} g H \frac{\partial(h-H)}{\partial y}+g \frac{\partial}{\partial y}\left(\int_{h-H}^{h} \int_{z}^{h} \rho \mathrm{d} z^{\prime} \mathrm{d} z^{\prime \prime}\right)
\end{aligned}
$$

and

$$
\begin{aligned}
\rho w= & \left(\dot{\varepsilon}_{x x}+\dot{\varepsilon}_{y y}\right) \int_{z}^{h} \rho \mathrm{d} z^{\prime}+u \frac{\partial}{\partial x}\left(\int_{z}^{h} \rho \mathrm{d} z^{\prime}\right) \\
& +v \frac{\partial}{\partial y}\left(\int_{z}^{h} \rho \mathrm{d} z^{\prime}\right)+\frac{\partial}{\partial t}\left(\int_{z}^{h} \rho \mathrm{d} z^{\prime}\right)-\rho_{\mathrm{c}} a_{\mathrm{s}}
\end{aligned}
$$

where

$$
\begin{gathered}
F=H \overline{A^{-\frac{1}{n}}} \dot{\varepsilon}^{\frac{1}{n}-1}, \dot{\varepsilon}_{x x}=\frac{\partial u}{\partial x}, \dot{\varepsilon}_{y y}=\frac{\partial v}{\partial y}, \dot{\varepsilon}_{x y}=\frac{1}{2}\left(\frac{\partial u}{\partial y}+\frac{\partial v}{\partial x}\right), \\
\dot{\varepsilon}^{2}=\dot{\varepsilon}_{x x}^{2}+\dot{\varepsilon}_{y y}^{2}+\dot{\varepsilon}_{x x} \dot{\varepsilon}_{y y}+\dot{\varepsilon}_{x y \prime}^{2}
\end{gathered}
$$

where $u$ and $v$ are the horizontal velocities of ice flow, $w$ is the vertical velocity, $\dot{\varepsilon}_{x x}, \dot{\varepsilon}_{y y}$ and $\dot{\varepsilon}_{x x}$ are the horizontal components of the strain-rate tensor, $\dot{\varepsilon}$ is the effective strain rate, $h$ the surface elevation above sea level, $H$ the ice thickness, $g$ the acceleration due to gravity, $\rho_{\mathrm{C}}$ the density of completely consolidated ice $\left(915 \mathrm{~kg} \mathrm{~m}^{-3}\right), a_{\mathrm{s}}$ the surface accumulation rate measured in $\mathrm{ma}^{-1}$ ice equivalent, and $t$ the time. The parameters $A$ and $n$ of Glen's flow law are predetermined as follows: the flow factor $A$ depends on ice temperature $T$ as indicated in Figure $1 \mathrm{a}$; the exponent $n$ is equal to 3. The ice density $\rho$ is specified by means of an appropriate constitutive relation, such as that shown in Figure $1 \mathrm{~b}$. Bars over parameters indicate depth-averaged values.

The heat-transfer equation completes the basic model equation set:

$$
\begin{aligned}
& \rho c_{\mathrm{p}} \frac{\partial T}{\partial t}=K \operatorname{div}(\operatorname{grad} T)+\frac{\partial K}{\partial T}(\operatorname{grad} T)^{2} \\
& -\rho c_{\mathrm{p}} \vec{u}(\operatorname{grad} T)+2 A^{-\frac{1}{n} \varepsilon^{\frac{1}{n}}+1},
\end{aligned}
$$

where $T$ is the ice temperature, $\vec{u}=(u, v, w)^{T}$ the velocity vector, $c_{\mathrm{p}}$ is the specific heat capacity, and $K$ the thermal conductivity. To compute ice velocities and temperatures for the respective iceberg geometry and density distribution, several boundary conditions must be specified.

While boundary values are prescribed for the mean annual surface temperature, $T_{\mathrm{s}}$, and the temperature at the iceberg base, $T_{\mathrm{b}}$, the iceberg front is treated as a perfectly heat-isolating interface. The only boundary condition 
required for the ice velocity is based on the balance of forces formulated for an ice edge of idealized rectangular shape (Weertman, 1957). If the ice flow takes place in the $x$ direction, perpendicular to the iceberg front, the condition reads:

$$
\begin{aligned}
\frac{\partial u}{\partial x}= & \frac{A^{-\frac{1}{n}}}{-1} \dot{\varepsilon}^{1-\frac{1}{n}} \frac{g}{2 H}\left(\int_{h-H}^{h} \int_{z}^{h} \rho \mathrm{d} z^{\prime} \mathrm{d} z^{\prime \prime}-\rho_{\mathrm{w}} \frac{(h-H)^{2}}{2}\right) \\
& -\frac{1}{2} \frac{\partial v}{\partial y} ; \quad \frac{\partial v}{d x}=-\frac{\partial u}{d y} .
\end{aligned}
$$

As this boundary condition is not unique, each velocity field $\vec{u}_{\text {tot }}$ of the form

$$
\begin{aligned}
\vec{u}_{\mathrm{tot}} & =\vec{u}+\sum_{l} \vec{u}_{\mathrm{rot} \mid l}+\vec{u}_{\mathrm{trans}} \\
& =\left(\begin{array}{l}
u \\
v
\end{array}\right)+\sum_{l} b_{l}\left(\begin{array}{c}
y-y_{l} \\
-x+x_{l}
\end{array}\right)+\left(\begin{array}{l}
u_{0} \\
v_{0}
\end{array}\right),
\end{aligned}
$$

where rigid-body rotations $\vec{u}_{\text {rot }}$ and a translation $\vec{u}_{\text {trans }}$ are superimposed on the velocity of ice flow $\vec{u}$, is still a solution of the set of Equations (1), (2) and (5). However, the superimposed velocity fields lead to spurious contributions to the advection in calculating temperature distribution or to the calculated thickness evolution (cf. Equations (4) and (7)) and may even cause divergences in the numerical solution of the model equations. Therefore, they are reduced instantaneously by the constraint of minimal kinetic energy.

The basic equation for calculating the evolution of iceberg geometry is the vertically integrated mass-balance equation which describes the temporal change in ice thickness (e.g. Paterson, 1994),

$$
\frac{\partial H}{\partial t}=\frac{\rho_{\mathrm{c}}}{\bar{\rho}}\left(a_{\mathrm{s}}+a_{\mathrm{b}}\right)-\frac{1}{\bar{\rho}}\left(\frac{\partial}{\partial x}(\bar{\rho} H u)+\frac{\partial}{\partial y}(\bar{\rho} H v)\right)-\frac{H}{\bar{\rho}} \frac{\partial \bar{\rho}}{\partial t},
$$

where $a_{b}$ is the basal mass balance measured in $\mathrm{ma}^{-1}$ ice equivalent. Iceberg thickness evolution is accompanied by surface elevation changes according to the hydrostatic relation $h=\left(1-\bar{\rho} / \rho_{\mathrm{w}}\right) H$, where $\rho_{\mathrm{w}}$ is the density of sea water.

The computation of an approximate solution of Equations (1-5) and (7) is performed using the same numerical procedures and model grid configuration as described by Grosfeld and Sandhäger (2004).

\section{STRAIN THINNING OF IDEALIZED ICEBERGS}

We performed a first series of numerical experiments to test main modules of the iceberg model and to gain insight into basic ice-dynamical characteristics of large tabular icebergs. The model was applied to strongly idealized icebergs, each with constant density $\left(915 \mathrm{~kg} \mathrm{~m}^{-3}\right)$ and temperature (i.e. the flow factor $A$ is also constant) and a rectangular shape with side lengths of 40 and $72 \mathrm{~km}$. The chosen iceberg surface area of $2880 \mathrm{~km}^{2}$ is consistent with typical values observed for large icebergs.

Assuming the idealized iceberg with a thickness of $250 \mathrm{~m}$ and a temperature of $-20^{\circ} \mathrm{C}$ is in steady state $(\partial H / \partial t=0)$, a diagnostic model run yields a radial horizontal flow velocity field symmetric to the center of gravity (Fig. 2):

$$
\vec{u}=\left(\begin{array}{l}
u \\
v
\end{array}\right)=a\left(\begin{array}{l}
x-x_{0} \\
y-y_{0}
\end{array}\right)
$$

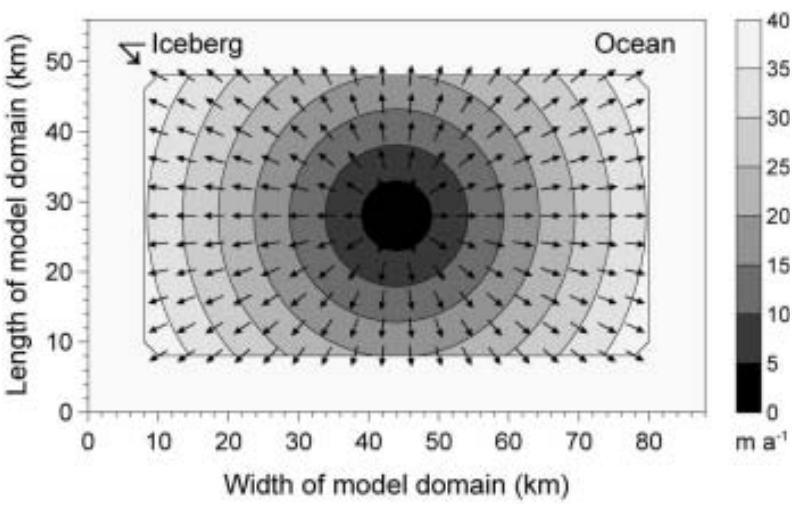

Fig. 2. Modeled radial distribution of the horizontal velocity of an idealized iceberg with constant temperature $\left(-20^{\circ} \mathrm{C}\right)$, density $\left(915 \mathrm{~kg} \mathrm{~m}^{-3}\right)$ and thickness $(250 \mathrm{~m})$. Arrows indicate the direction of ice flow.

with $a \approx 9.84 \times 10^{-4} \mathrm{a}^{-1}, \quad x_{0}=44 \mathrm{~km}$ and $y_{0}=28 \mathrm{~km}$ complying with Equations (1) and (2). The value for a derived analytically by inserting Equation (8) in the boundary condition given by Equation (5) agrees well with the model results:

$$
a=3 A\left(\frac{g h \rho_{\mathrm{c}}}{6}\right)^{3}=9.89 \times 10^{-4} \mathrm{a}^{-1} .
$$

Next we performed a time-dependent model run for an idealized iceberg with an initial thickness of $500 \mathrm{~m}$, a temperature of $-20^{\circ} \mathrm{C}$ and no vertical mass exchange $\left(a_{\mathrm{s}}=a_{\mathrm{b}}=0\right)$. Ice-front erosion and migration were ignored. During the simulation period of 250 years, the iceberg thickness decreased to $213 \mathrm{~m}$ due to strain thinning. Figure 3a shows strain thinning rates with respect to iceberg thickness derived from model results. Additionally, thinning rates for different ice temperatures and flow factors, respectively, were calculated as follows:

$$
\frac{\partial H}{\partial t}=-2 H a=-6 H A\left(\frac{g h \rho_{\mathrm{c}}}{6}\right)^{3}=-6 A\left[\frac{g \rho_{\mathrm{c}}}{6}\left(1-\frac{\rho_{\mathrm{c}}}{\rho_{\mathrm{w}}}\right)\right]{ }^{3} H^{4},
$$

which results directly from insertion of the velocity distribution described by Equation (8) into the continuity equation for ice thickness (Equation (7)) for an idealized iceberg with constant density. Model results agree well with the analytical solution (10). This is also clear in Figure $3 b$, where the norm of the horizontal velocity vector at $20 \mathrm{~km}$ distance to the center of gravity is plotted vs iceberg thickness. Analytical curves of flow velocity in Figure $3 b$ are based on the equation

$$
\begin{aligned}
& |\vec{u}|=a \sqrt{\left(x-x_{0}\right)^{2}+\left(y-y_{0}\right)^{2}} \\
& =3 A\left[\frac{g \rho_{\mathrm{c}}}{6}\left(1-\frac{\rho_{\mathrm{c}}}{\rho_{\mathrm{w}}}\right)\right]{ }^{3} H^{3} \sqrt{\left(x-x_{0}\right)^{2}+\left(y-y_{0}\right)^{2}} .
\end{aligned}
$$

As real Antarctic tabular icebergs often comprise thickness gradients in the order of a few meters per kilometer, which developed in their pre-calving states as a result of the characteristic seaward ice-shelf spreading, we performed further model runs with icebergs still strongly idealized but containing a thickness gradient. The model results shown in Figure 4 indicate that the influence of typical ice-thickness gradients on strain thinning is negligible. Thus, the findings 

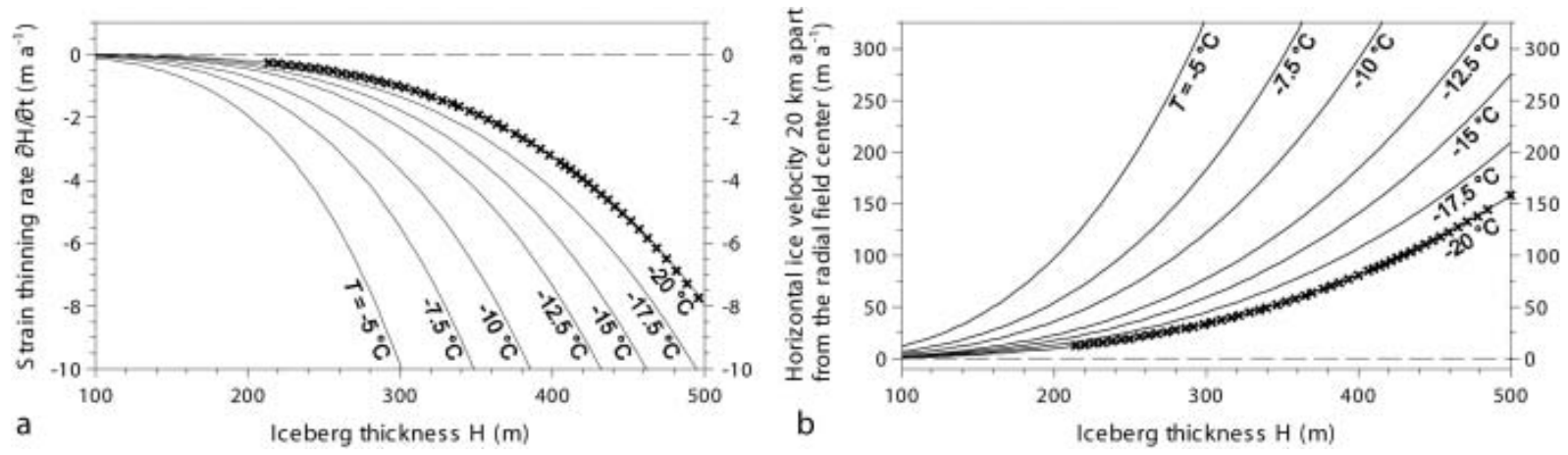

Fig. 3. (a) Variation of strain thinning rate $\partial H / \partial t$ with thickness $H$ and temperature $T$ of a rectangular isothermal iceberg with constant density $\left(915 \mathrm{~kg} \mathrm{~m}^{-3}\right.$ ), based on analytical calculations of Equation (10); crosses indicate results from a time-dependent application of the iceberg model. (b) Corresponding diagram of horizontal ice velocity $20 \mathrm{~km}$ from the radial field center vs iceberg thickness and temperature, based on Equation (11).

in Figure 3 provide a basis for pre-estimating strain thinning of real tabular icebergs with a roughly known thickness and mean temperature. According to the model results, an average iceberg with a thickness of $250 \mathrm{~m}$ and a mean temperature of $-15^{\circ} \mathrm{C}$ is subject to a strain thinning rate of about $1 \mathrm{ma}^{-1}$. This contribution to thickness decrease is probably of the same order of magnitude as basal melting in the southern Weddell Sea (Schodlok and others, 2005). However, at lower latitudes, where basal melting enhances significantly, strain thinning becomes less important to iceberg evolution.

\section{EXPERIMENTS FOR ICEBERGS INTERACTING WITH OCEAN AND ATMOSPHERE}

Approaching more realistic simulations of the evolution of tabular icebergs, we carried out a second series of model studies with essentially reduced simplifications compared with the strongly idealized basic experiments. In particular, we included the impact of ocean and atmosphere on iceberg evolution and considered variable density and temperature distributions.

An equation of state established for the Ronne Ice Shelf determines the density profile, which comprises a gradual change from snow to firn and finally to completely

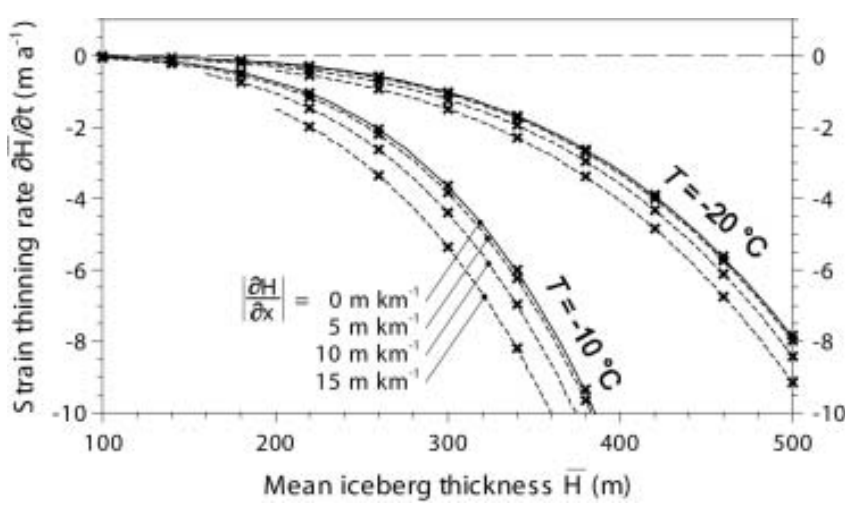

Fig. 4. Variation of strain thinning rate $\partial \bar{H} / \partial t$ with mean iceberg thickness $\bar{H}$ for different ice temperatures and longitudinal thickness gradients $\partial H / \partial x$. Model results (dashed curves and crosses) obtained for an idealized isothermal iceberg of constant density $\left(915 \mathrm{~kg} \mathrm{~m}^{-3}\right)$ match the curves for $\partial H / \partial x=0$ which are derived from analytical calculations of Equation (10). consolidated ice within about the uppermost $100 \mathrm{~m}$ of the iceberg (Fig. 1b). The initial temperature distribution is based on borehole measurements at a drilling site near the Ronne Ice Shelf front (Figs 1c and 5a; Grosfeld and Thyssen, 1994), which delivered a temperature-depth profile indicating approximate thermal equilibrium with moderate basal melting. However, the heat-transfer relation, Equation (4), determines the time-dependent variation of the temperature distribution during iceberg evolution. The dimensions of the tabular iceberg are set to $56 \mathrm{~km} \times 136 \mathrm{~km}$ with a thickness of $230 \mathrm{~m}$, i.e. similar to the geometry of iceberg A-38. Possible ice-front migration during the simulation time of 5 years is neglected, and temporal resolution of the simulation is 0.25 years.

To investigate separately the impact of interactions with ocean and atmosphere on iceberg evolution, we performed model applications for two scenarios of environmental conditions (Fig. 5a and c). The first scenario focused on iceberg-ocean interaction, the second on changes in atmospheric conditions. In the ocean experiment, the basal mass balance $a_{b}$ was specified to change from pronounced melting to accumulation of marine ice along the longitudinal axis of the iceberg, but was constant with time. No mass exchange was allowed at the iceberg surface $\left(a_{\mathrm{s}}=0\right)$ and mean annual surface temperature was set constant with time at $T_{\mathrm{s}}=-23.2^{\circ} \mathrm{C}$. In the second scenario, the surface mass balance was specified to change linearly from ablation of $a_{\mathrm{s}}=-5 \mathrm{~m} \mathrm{a}^{-1}$ ice equivalent to accumulation of $\mathrm{a}_{\mathrm{s}}=1 \mathrm{~m} \mathrm{a}^{-1}$ ice equivalent along the longitudinal axis of the iceberg. There was no basal melting for the entire iceberg. The surface temperature increased with time.

Compared to the initial configuration of the iceberg, which showed a radial symmetric distribution of the horizontal flow velocity, obvious differences appear in the resulting evolution of the iceberg scenarios, influenced by the prevailing environmental conditions (Fig. $5 \mathrm{~d}$ and e). In scenario I, the enhanced basal melting causes erosion of the relatively warm ice in the lower part of the iceberg, leading to strong vertical temperature gradients above the iceberg base. In contrast, basal accumulation processes at the other end of the profile result in an increase in thickness due to the formation of marine ice with temperatures just below the freezing point. Using the numerical approach presented by Grosfeld and Sandhäger (2004), the maximum thickness of marine ice after 5 years was calculated to be about $24.7 \mathrm{~m}$. Furthermore, the temperature distribution for scenario I 


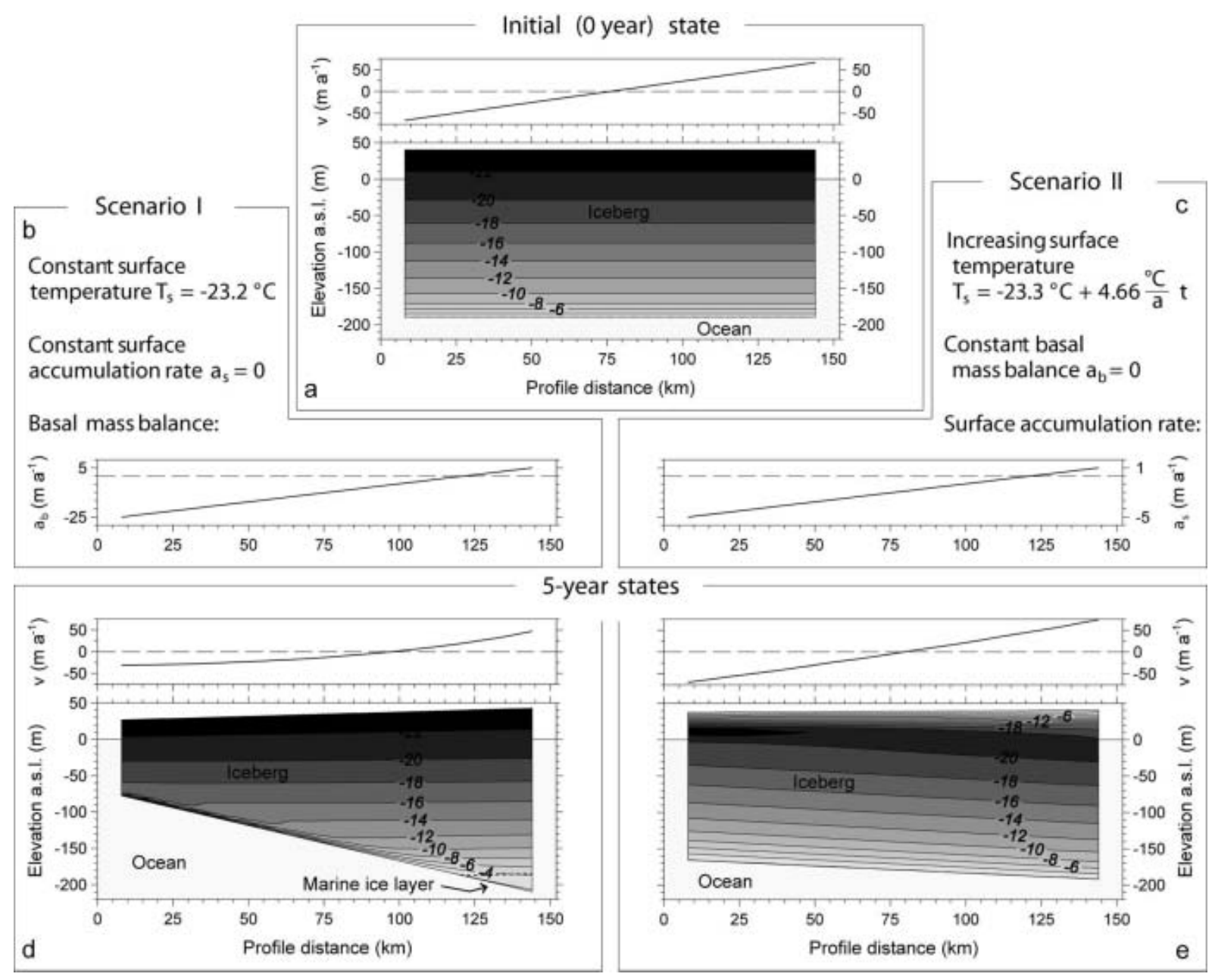

Fig. 5. Simulated evolution of a tabular iceberg interacting with ocean and atmosphere for a constant surface area of $56 \mathrm{~km} \times 136 \mathrm{~km}$. (a) Initial horizontal velocity $v$ and vertical distribution of temperature $T$ (in ${ }^{\circ} \mathrm{C}$ ) along the longitudinal iceberg axis; (b, c) prescribed climatic boundary conditions for scenarios I and II; (d, e) distributions of $v$ and Talong the longitudinal iceberg axis after 5 years of integration under environmental conditions I and II, respectively. Spatial variations of forcing parameters only occur in profile direction.

presented in Figure $5 d$ shows the minor importance of heat conduction within the ice body. The center of the horizontal radial velocity field shifted towards the section with greater thickness and higher temperatures.

The boundary conditions of scenario II induced the migration of the temperature minimum to the inner part of the iceberg. A negative mass balance caused a steep temperature gradient (Fig. 5e) related to a temperature minimum close to the iceberg surface. Accumulation shifted this minimum to deeper layers. However, the temperature distribution in the central and lower part of the iceberg was not influenced significantly during the 5 year period. Strain thinning amounted to about $0.5 \mathrm{ma}^{-1}$ (Fig. 3a) for both environmental settings, and is therefore a minor effect compared to mass exchanges with ocean and atmosphere.

\section{ICEBERG A-38}

\section{Observed evolution}

Considering the results of these numerical studies, we are confident that the model provides realistic time-dependent simulations of the development of idealized tabular icebergs with respect to inherent ice dynamics and fundamental exterior parameters. As a next step, we applied the model to a real Antarctic tabular iceberg, which was selected using the following criteria: the initial iceberg geometry and its temperature profile are well known; the iceberg has been subject to a long-distance drift associated with significant changes in environmental conditions; and observations and supplementary data are sufficient to provide a reliable description of the iceberg evolution. All these demands are met by iceberg A-38, whose evolution will be briefly described and documented by satellite images (US National Oceanic and Atmospheric Administration (NOAA) Defense Meteorological Satellite Program (DMSP); moderate-resolution imaging spectroradiometer (MODIS); RADARSAT; Envisat) in the following. The Antarctic Iceberg Database (Brigham Young University, Provo, Utah, USA), which is based on satellite-borne scatterometer data, provided the drift track.

In October 1998 the giant tabular iceberg A-38 calved off the Ronne Ice Shelf west of Berkner Island, where several pronounced slow-growing inlets characterized the structure of the ice shelf. The crack which led to this calving event followed the connecting line between two inlet tips, forming a tabular iceberg with an approximate size of $150 \mathrm{~km} \times 50 \mathrm{~km}$. The calving process probably occurred on a very short time-scale.

Iceberg A-38 was first detected on 15 October 1998, by NOAA DMSP satellite. Following a collision with the 

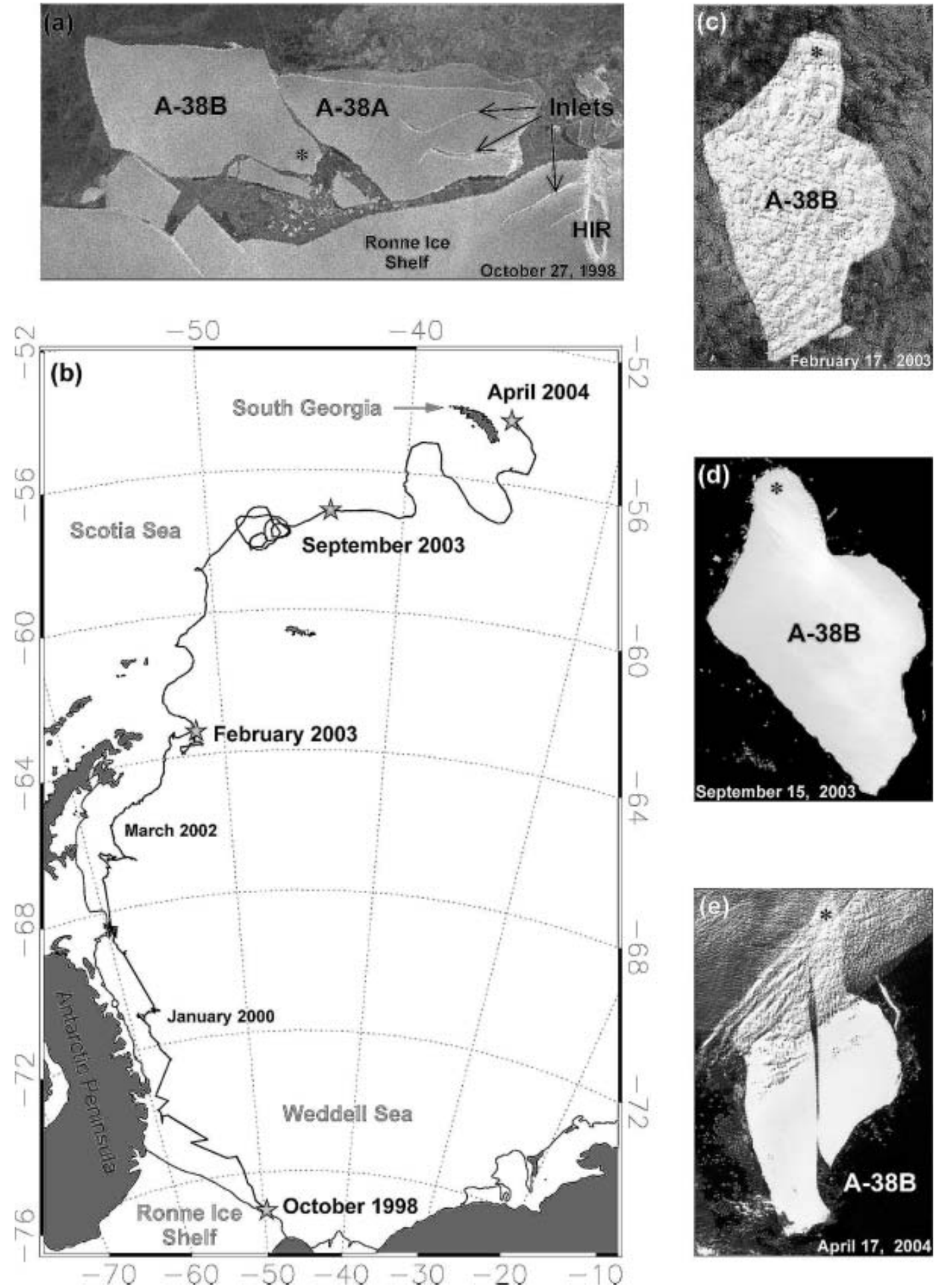

Fig. 6. (a) Major fracture events occurred in October 1998, when A-38 calved and broke into parts A and B (RADARSAT ScanSAR image (C) Canadian Space Agency, 1998); HIR: Hemmen Ice Rise. (b) Map of Weddell Sea and Scotia Sea, with drift trajectory of large tabular iceberg A-38B. (c-e) Satellite images showing different stages of the A-38B evolution (MODIS images partly with clouds; image courtesy of MODIS Rapid Response Team, NASA Goddard Space Flight Center). In austral autumn 2004, A-38B broke up into several pieces during a phase of grounding near South Georgia. The stars on A-38B images serve for orientation.

ice-shelf front shortly after calving, A-38 broke into two parts of about equal size: A-38A, formerly the eastern part, still containing two major inlets of $40 \mathrm{~km}$ length, and A-38B, the western part, on which we focus in this study (Fig. 6a). A-38B drifted within the Weddell Gyre towards the Antarctic Peninsula and then followed the coastline northwards (Fig. 6b). The drift velocity varied strongly with sea-ice coverage and thickness, including periods of stagnation. In
February 2003, the iceberg reached the tip of the Antarctic Peninsula and proceeded further north, leaving the area of permanent sea-ice coverage. An optical satellite image (MODIS) shows A-38B on 17 February 2003 (Fig. 6c).

In the Scotia Sea, the iceberg accelerated considerably and reached South Georgia by December 2003. A-38B passed the island to the east and grounded in January 2004 northeast of South Georgia. During the drift the iceberg 


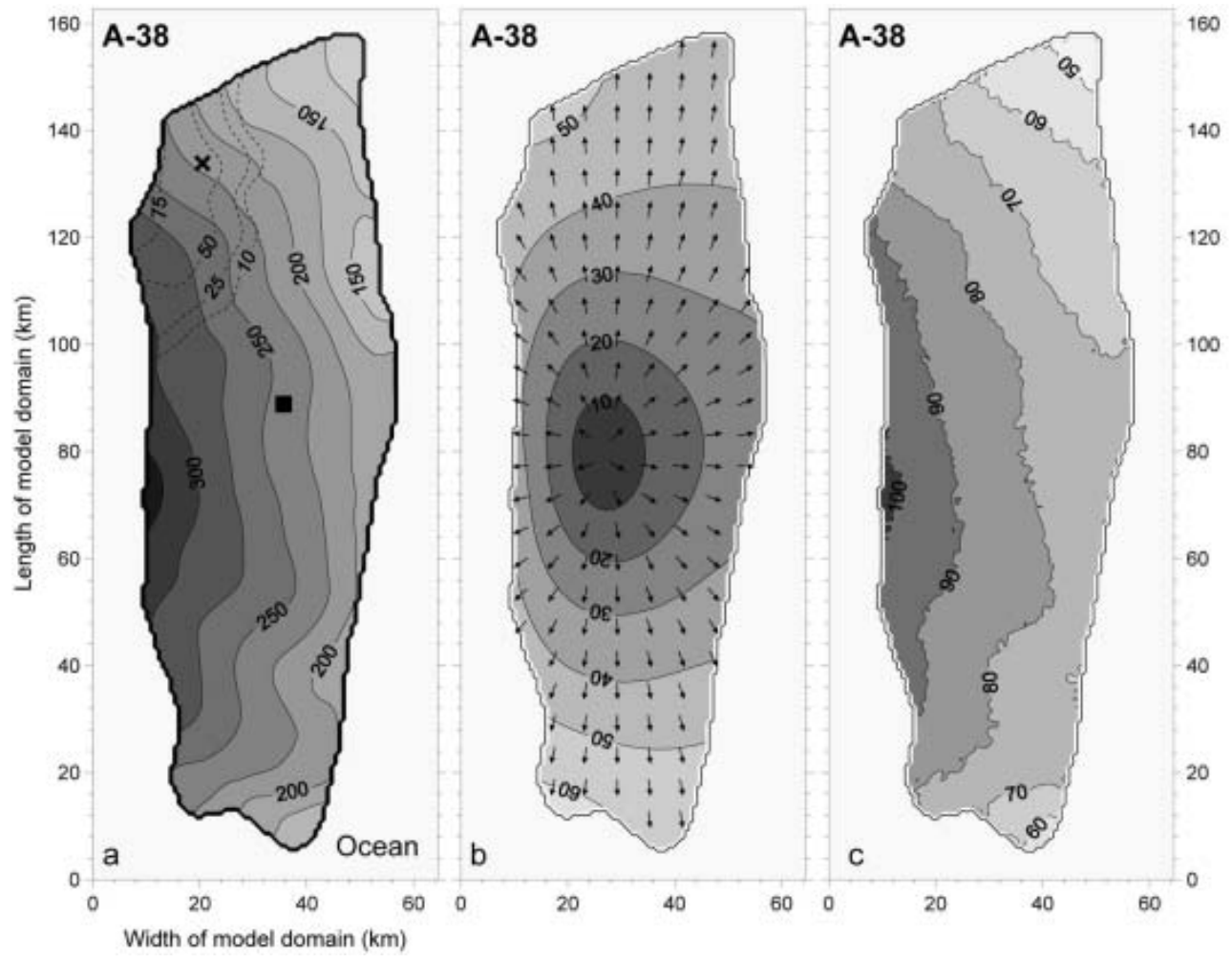

Fig. 7. Diagnostic model results for the large Antarctic iceberg A-38. (a) Prescribed distribution of total ice thickness $H$ (in $\mathrm{m}$ ). The locations of the former Filchner-Station and the drill site which provided the temperature-depth profile shown in Figure 1 are marked with a square and cross, respectively. Dashed contours indicate the thickness $H_{\text {mar }}$ of a basal marine ice layer formed prior to the separation of A-38 from Ronne Ice Shelf. (b) Horizontal velocity field describing the direction and magnitude (in $\mathrm{m} \mathrm{a}^{-1}$ ) of iceberg spreading. (c) Distribution of effective deviatoric stress $\tau$ (in $\mathrm{kPa}$ ) near the iceberg surface.

shape changed insignificantly, except for small-scale calving at its margins (Fig. 6d). On 15 April 2004, A-38B broke into two nearly equal-sized parts (Fig. 6e). The part located closer to the island remained grounded, while the other part drifted northwards. The grounded iceberg fragment broke into several pieces during August and September 2004 (Jansen and others, 2005).

\section{Diagnostic model run}

We first performed a diagnostic simulation of the ice dynamics of A-38 immediately after calving, to examine the velocity and the corresponding stress field for an anomaly which could have supported the later crack formation. The shape of the iceberg was obtained from RADARSAT images, and the corresponding ice-thickness distribution derived from a digital ice-thickness model of the Filchner-Ronne Ice Shelf (Sandhäger and others, 2004) as shown in Figure $7 \mathrm{a}$. The thickness varies from about $300 \mathrm{~m}$ at the crack line to about $150 \mathrm{~m}$ at the former ice-shelf front, yielding a gradient of about $3 \mathrm{~m} \mathrm{~km}^{-1}$ along the shorter axis of the iceberg. Surface height above sea level is determined by the hydrostatic relation,

$$
h=0.108 H+15.5 m
$$

according to the density distribution shown in Figure $1 \mathrm{~b}$.

The initial vertical temperature distribution (Fig. 1c) was derived from borehole measurements at the drilling site near the Ronne Ice Shelf front (Grosfeld and Thyssen, 1994; the position of the drilling site is marked in Figure 7a). Results of radio-echo sounding surveys indicated marine ice beneath A-38, or later A-38B, reaching a maximum thickness of
$>75 \mathrm{~m}$ (Thyssen and others, 1993; Fig. 7a). As the temperature profile does not show any anomalies, and the density difference between marine and meteoric ice is small (Oerter and others, 1992), no differentiation between marine and meteoric ice was included in the model calculations.

The model grid had a horizontal resolution of $750 \mathrm{~m}$; the vertical resolution is analogous to the model settings described above. The resulting velocity field of the diagnostic run for iceberg A-38 is presented in Figure $7 \mathrm{~b}$. It shows radial symmetry, although the influence of thickness distribution can be seen in some areas of the iceberg: for example, the position of zero velocity was shifted towards maximum thickness. According to Figure 4, an initial strain thinning of about $0.5 \mathrm{ma}^{-1}$ should be expected. The estimation of flow velocity $20 \mathrm{~km}$ from the position of zero velocity (Fig. 3 b) gave about $25 \mathrm{~m} \mathrm{a}^{-1}$, which fits well with the model results.

The corresponding stress field for the iceberg does not show pronounced anomalies which might be regarded as potential areas for spontaneous crack formation. However, the effective deviatoric stress near the ice surface $\tau_{\mathrm{s}}$ (Fig. 7c) is closely correlated with the thickness distribution, reaching a maximum of about $100 \mathrm{kPa}$ at the position of greatest thickness. This is also the position where the crack initiated which split A-38 in two (cf. Fig. 6a). According to Vaughan (1993), the surface tensile strength $\sigma_{\text {crit }}$ for the Ronne Ice Shelf is in the range $190-250 \mathrm{kPa}$, corresponding to a critical deviatoric stress of $110-144 \mathrm{kPa}$. This may explain why the crack started at the position of maximum iceberg thickness. 


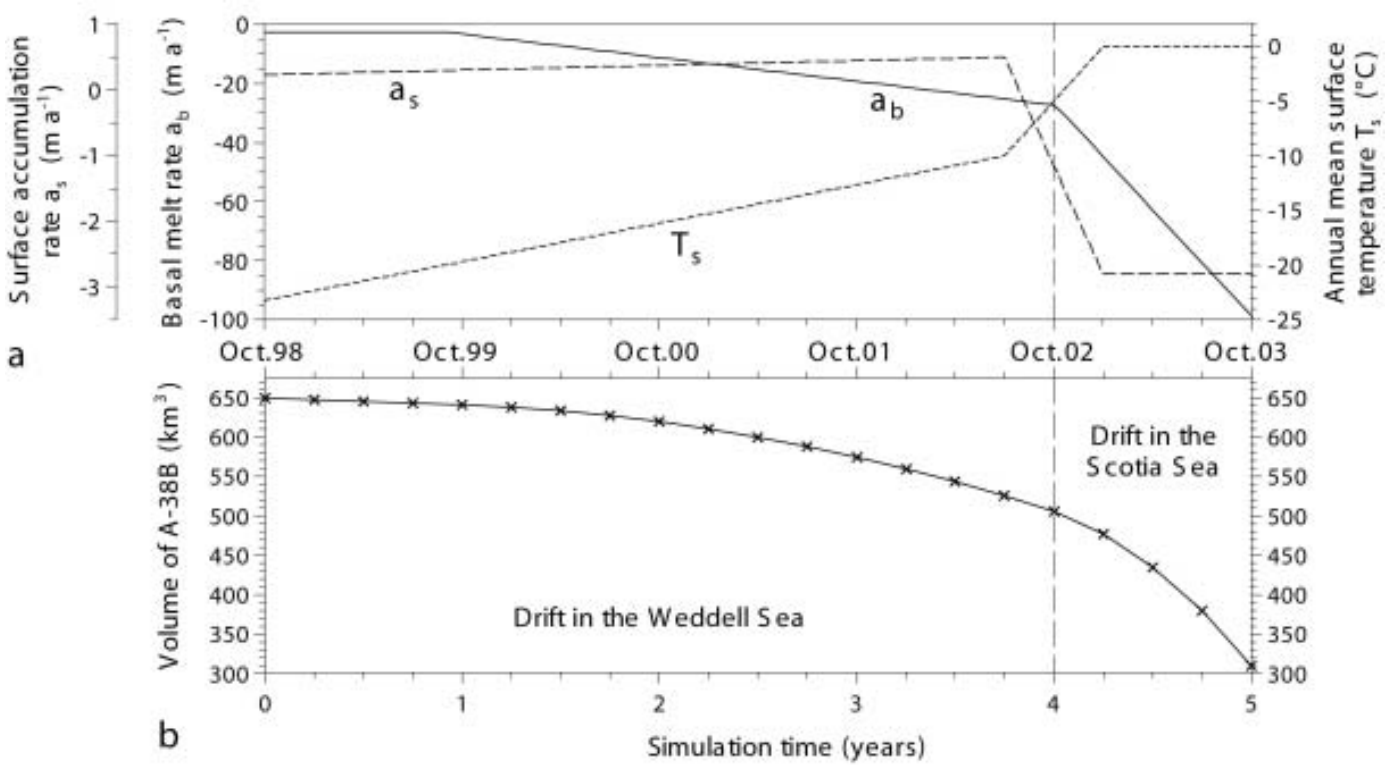

Fig. 8. Simulated evolution of large iceberg A-38B, October 1998-October 2003. (a) Prescribed climate forcing due to temporal variations in surface accumulation, surface temperature and basal melting. (b) Modeled decrease in iceberg volume. As of austral spring 2002, when A-38B entered the Scotia Sea, the iceberg has been subject to a strong warming and, hence, reinforced decay.

\section{Simulated evolution}

For the simulation over 5 years, starting in October 1998, we chose iceberg A-38B, since A-38A contained pronounced inlets representing significant anomalies of geometry, and their probable influence on ice dynamics is not yet implemented in the model. The simulation period October 1998-October 2003 comprises the iceberg's drift from its origin at the Ronne Ice Shelf front west of Berkner Island to its grounding position northeast of South Georgia. The forces affecting the iceberg during the grounding phase are not yet considered in the model, therefore the grounding of the iceberg defines the end of the simulation period. To provide for reliable temporal and spatial resolution, we chose a simulation time-step of 0.25 year and a horizontal grid spacing of $2.25 \mathrm{~km}$.

The interaction with ocean and atmosphere under changing environmental conditions during the drift determines the model boundary conditions. Figure $8 \mathrm{a}$ shows the prescribed basal and surface mass balances, which are the dominant forcing terms of the evolution model, as well as surface temperature as a function of simulation time.

Annual mean surface temperature at the beginning of the drift was set to $-23.2^{\circ} \mathrm{C}$, according to measurements at the Filchner-Station (Grosfeld and Thyssen, 1994). As the iceberg reached the latitude of the northern Larsen Ice Shelf section in June 2002, the surface temperature was assumed to be $-10^{\circ} \mathrm{C}$ based on local measurements (Morris and Vaughan, 2003), and interpolated linearly to the starting temperature. For the following transition from the Weddell Sea to the Scotia Sea, the mean surface temperature of the iceberg rose rapidly to the melting point, as suggested by European Centre for Medium-Range Weather Forecasts (ECMWF) model data.

Surface mass balance at the beginning of the drift was set to $0.233 \mathrm{~m} \mathrm{a}^{-1}$ ice equivalent (Graf and others, 1988) and increased to $0.5 \mathrm{~m} \mathrm{a}^{-1}$ ice equivalent by the time the iceberg reached the northern Larsen Ice Shelf in June 2002 (Vaughan and others, 1999). In the Scotia Sea it was estimated by means of the positive degree-day model (Braithwaite and Olesen, 1989) at $-2.8 \mathrm{~m} \mathrm{a}^{-1}$ ice equivalent. For simplicity we assume that surface ablation processes only cause a mass loss of the iceberg. Meltwater formation and associated impact on iceberg evolution from percolation, refreezing or changes in the overall albedo are neglected.

The basal melt rate was based on model data (Lichey and Hellmer, 2001) and estimated at $2.7 \mathrm{~m} \mathrm{a}^{-1}$ for the first year of iceberg drift. During the following 3 years, basal melting was specified to increase linearly to $27.2 \mathrm{ma}^{-1}$. From October 2002 to October 2003 the basal melt rate was increased dramatically to $98.6 \mathrm{~m} \mathrm{a}^{-1}$ due to stronger currents and warmer ocean water in the Scotia Sea (Schodlok and others, 2005).

Figure $8 \mathrm{~b}$ shows the iceberg volume with respect to simulation time. Owing to the increasing basal mass loss, the iceberg volume decreased continuously with time, leading to a change of volume from $650 \mathrm{~km}^{3}$ to $525 \mathrm{~km}^{3}$ after 3.75 years. In the following period the erosion accelerated because of the dramatically rising basal melt rates, so that after 5 years, only $310 \mathrm{~km}^{3}$ or $48 \%$ of the iceberg still existed. A slight reduction of the surface area occurred only during the last modeled evolution stage. Of the overall decrease in iceberg thickness from $220 \mathrm{~m}$ to $106.3 \mathrm{~m}, 95 \%(108.0 \mathrm{~m})$ was caused by basal melting, $1 \%(1.2 \mathrm{~m})$ by surface melting and $4 \%(4.5 \mathrm{~m})$ by strain thinning. The mean strain thinning rate of $0.9 \mathrm{ma}^{-1}$ is of the same order of magnitude as the estimation of $0.3 \mathrm{~m} \mathrm{a}^{-1}$ derived from Figures $3 a$ and 4 . Model results, therefore, indicate that mass exchange with the ocean is the decisive process in the evolution of the geometry of iceberg A-38B.

Essential iceberg characteristics of the initial and final states are compared in Figure 9. The significant and homogeneous decrease in iceberg thickness led to a slight surface area reduction of $30 \mathrm{~km}^{2}$. Gridcells in which the thickness fell below a threshold of $10 \mathrm{~m}$ were neglected, representing a kind of calving criterion. The break-up of A-38B shortly after grounding indicates that the thickness of 


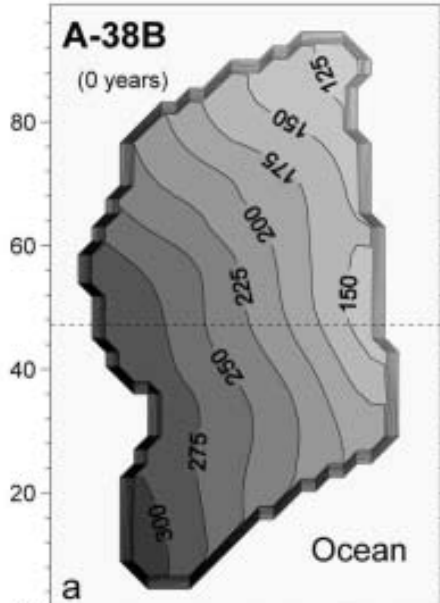

0.

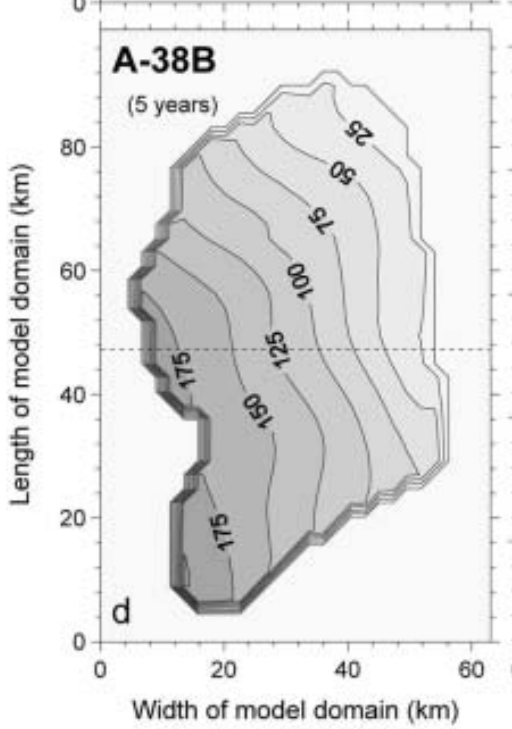

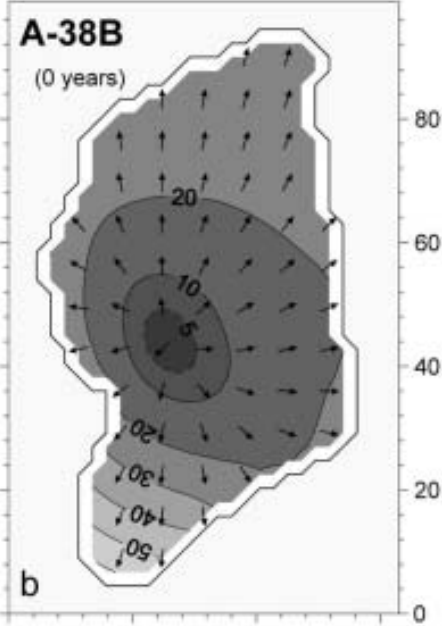

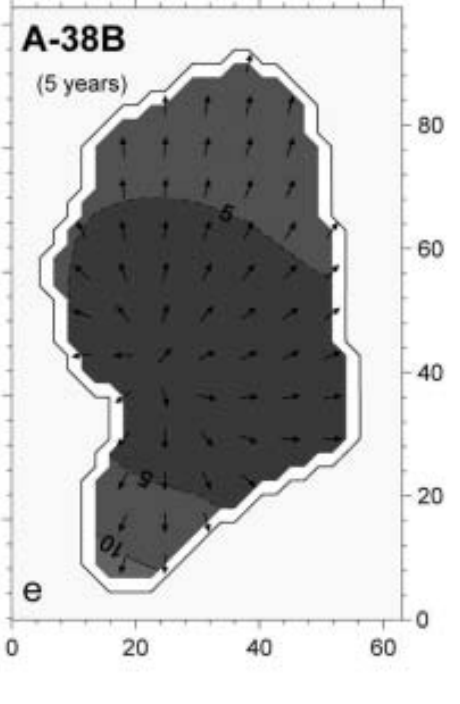

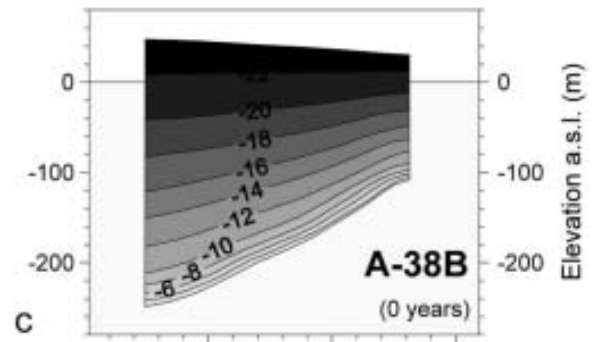

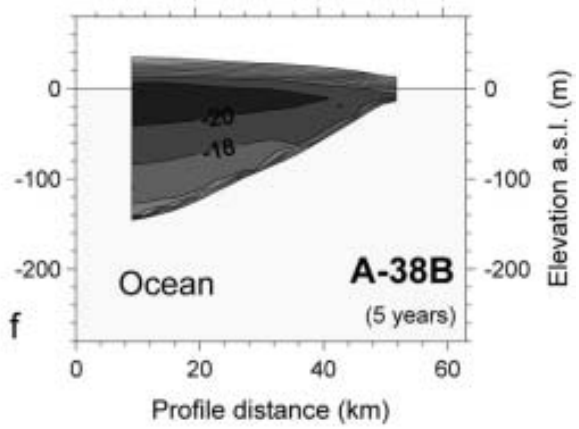

Fig. 9. Comparison between the initial and 5 year states of the simulated evolution of large iceberg A-38B: (a, d) distributions of total ice thickness $H$ (in m); (b, e) horizontal velocity fields describing the direction and magnitude (in $\mathrm{m} \mathrm{a}^{-1}$ ) of iceberg spreading; (c, f) selected vertical cross-sections with iceberg temperatures (in ${ }^{\circ} \mathrm{C}$ ). The profiles are marked with dashed lines in the ice-thickness maps. The decrease in iceberg surface area of about $30 \mathrm{~km}^{2}$ was imposed by defining a threshold of $10 \mathrm{~m}$ for minimum iceberg thickness.

the observed iceberg may indeed have approached a critical value, at least in some parts (Fig. 6e). Assuming a basal melt rate of several tens of $\mathrm{m} \mathrm{a}^{-1}$ further on, the final decay of iceberg A-38B can be expected soon.

A comparison between Figure $9 \mathrm{~b}$ and e reveals the sensitivity of horizontal flow to iceberg thickness, not affecting the radial symmetry of the velocity field. The mean velocity of $4 \mathrm{~m} \mathrm{a}^{-1}$ at the end of the simulation is much lower than the initial velocity of about $20 \mathrm{~m} \mathrm{a}^{-1}$, leading to a negligible strain thinning rate.

Vertical cross-sections along the shorter iceberg axis for the initial and final stages (Fig. 9c and f) demonstrate the considerable impact of environmental conditions on the temperature distribution. Increasing temperatures along the drift track in combination with enhanced melting cause the erosion of the relatively warm basal ice layers and the occurrence of extreme temperature gradients at the top and bottom of the iceberg. In contrast, temperatures in the inner part remain nearly constant. This special temperature regime of a temperature minimum shifted to the inner part, and strong gradients at the boundaries may be important for possible fracture mechanics during the final decay.

\section{CONCLUSIONS}

The newly developed iceberg model can be considered an appropriate tool for investigating large tabular iceberg evolution. Although the current model version considers only one class of elementary influencing processes, a series of basic and advanced simulations yielded important findings on the relative significance of these processes. The model results indicate that mass release to the ocean due to basal melting is the primary cause of change in iceberg geometry during drift, whereas strain thinning associated with iceberg spreading is largely negligible. Effects of iceberg-atmosphere interaction seem to be significant mainly in the late stages of the evolution when the iceberg has approached lower latitudes and strong surface ablation occurs. Thus, it appears that the reliability of our model depends strongly on the accuracy of the forcing data determining basal melting along the drift trajectories. Whether melt-rate estimates from ocean models, which currently provide the only available comprehensive datasets, meet these accuracy requirements will remain unclear until suitable observations have been conducted. In particular, we need thickness data from tabular icebergs in the mid- and 
late stages of evolution to enable detailed validation of model results crucial for changes in iceberg geometry. Satellite image sequences of many large Antarctic icebergs reveal that surface area alteration is typically small over long periods, but they conceal the significant reduction in iceberg volume due to basal erosion.

To include other important processes in iceberg evolution, extension and modification of the model is necessary. A decisive task will be to investigate the role of local geometric anomalies, such as the mélange-filled inlets of iceberg A-38A, which had a significant influence on ice dynamics in the pre-calving stage (MacAyeal and others, 1998). Including fracturing on various scales could be a further advancement of the model. This complex problem requires detailed studies of possible fracture mechanisms and an adequate parameterization of the relevant mechanical processes. However, existing studies on fracture formation and propagation in ice shelves already provide a basis for this part of the model adaptations (e.g. Scambos and others, 2000; Rist and others, 2002).

Observations indicate that external forces due to ocean waves, currents and iceberg grounding also affect the evolution and decay of tabular icebergs, and they will therefore be considered in subsequent model versions.

An extended model version may yield important insights, especially for the later stages of iceberg evolution and for the final decay. As drifting large tabular icebergs represent large natural ice bodies under the influence of rapidly changing climatic boundary conditions (e.g. atmospheric and/or ocean warming), we assume that findings from iceberg evolution simulations will be of interest to the broader community.

\section{ACKNOWLEDGEMENTS}

The authors thank M. Pfuff and J. Schicker of the GKSS Forschungszentrum, Geesthacht, Germany, for helpful discussion on potential fracture processes in ice shelves and icebergs. We thank the reviewers D.R. MacAyeal and J.-B. Minster for valuable comments and suggestions. M. Schod-lok supplied the melt-rate estimates for iceberg A-38B. The Canadian Space Agency provided the image of RADARSAT data of tabular icebergs A-38A and A-38B. The MODIS images were made available by the MODIS Rapid Response Project at NASA Goddard Space Flight Center. ECMWF data used in this project have been obtained by the ECMWF data server. This work was supported by the Deutsche Forschungsgemeinschaft under grant SA 1029/1-1.

\section{REFERENCES}

Ballantyne, J. 2002. A multidecadal study of the number of Antarctic icebergs using scatterometer data. In Proceedings of IGARSS'02, Toronto, Ont., Canada, June 24-28, 2002. Vol. 5, 3029-3031.

Braithwaite, R.J. and O.B. Olesen. 1989. Calculation of glacier ablation from air temperature, West Greenland. In Oerlemans, J., ed. Glacier fluctuations and climatic change. Dordrecht, Kluwer Academic Publishers, 219-233.

Gladstone, R.M., G.R. Bigg and K.W. Nicholls. 2001. Iceberg trajectory modeling and meltwater injection in the Southern Ocean. J. Geophys. Res., 106(C9), 19,903-19,915.

Graf, W., H. Moser, H. Oerter, O. Reinwarth and W. Stichler. 1988. Accumulation and ice-core studies on Filchner-Ronne Ice Shelf, Antarctica. Ann. Glaciol., 11, 23-31.
Grosfeld, K. and H. Sandhäger. 2004. The evolution of a coupled ice shelf-ocean system under different climate states. Global Planet. Change, 42(1-4), 107-132.

Grosfeld, K. and F. Thyssen. 1994. Temperature investigation and modeling on the Filchner-Ronne Ice Shelf, Antarctica. Ann. Glaciol., 20, 377-385.

Grosfeld, K., M. Schröder, E. Fahrbach, R. Gerdes and A. Mackensen. 2001. How iceberg calving and grounding change the circulation and hydrography of Filchner Ice Shelfocean system. J. Geophys. Res., 106(C5), 9039-9056.

Jacobs, S.S., H.H. Hellmer, C.S.M. Doake, A. Jenkins and R.M. Frolich. 1992. Melting of ice shelves and the mass balance of Antarctica. J. Glaciol., 38(130), 375-387.

Jansen, D., H. Sandhäger and W. Rack. 2005. Evolution of tabular iceberg A-38B, observation and simulation. FRISP Report 16, $13-17$.

Lichey, C. and H.H. Hellmer. 2001. Modeling giant-iceberg drift under the influence of sea ice in the Weddell Sea, Antarctica. J. Glaciol., 47(158), 452-460.

MacAyeal, D.R., S. Shabtaie, C.R. Bentley and S.D. King. 1986. Formulation of ice shelf dynamic boundary conditions in terms of a Coulomb rheology. J. Geophys. Res., 91(B8), 8177-8191.

MacAyeal, D.R., E. Rignot and C.L. Hulbe. 1998. Ice-shelf dynamics near the front of the Filchner-Ronne Ice Shelf, Antarctica, revealed by SAR interferometry: model/interferogram comparison. J. Glaciol., 44(147), 419-428.

Morris, E.M. and D.G. Vaughan. 2003. Spatial and temporal variation of surface temperature on the Antarctic Peninsula and the limit of viability of ice shelves. In Domack, E., A. Leventer, A. Burnett, R.A. Bindschadler, P. Convey and M. Kirby, eds. Antarctic Peninsula climate variability historical and paleoenvironmental perspectives. Washington, DC, American Geophysical Union, 61-68. (Antarctic Research Series 79.)

Nøst, O.A. and S. Østerhus. 1998. Impact of grounded icebergs on the hydrographic conditions near the Filchner Ice Shelf, Antarctica. In Jacobs, S.S. and R.F. Weiss, eds. Ocean, ice and atmosphere: interactions at the Antarctic Continental Margin. Washington, DC, American Geophysical Union, 269-286. (Antarctic Research Series 75.)

Oerter, H., C. Drücker, J. Kipfstuhl, U. Nixdorf and W. Graf. 1992. The Filchner IV campaign and the $320 \mathrm{~m}$ deep ice core B15. FRISP Report 6, 47-53.

Paterson, W.S.B. 1994. The physics of glaciers. Third edition. Oxford, etc., Elsevier.

Rist, M.A., P.R. Sammonds, H. Oerter and C.S.M. Doake. 2002. Fracture of Antarctic shelf ice. J. Geophys. Res., 107(B1). (10.1029/2000JB000058.)

Sandhäger, H., D.G. Vaughan and A. Lambrecht. 2004. Meteoric, marine and total ice thickness maps of Filchner-Ronne-Schelfeis, Antarctica. FRISP Report 15, 23-29.

Scambos, T.A., C. Hulbe, M. Fahnestock and J. Bohlander. 2000. The link between climate warming and break-up of ice shelves in the Antarctic Peninsula. J. Glaciol., 46(154), 516-530.

Schodlok, M., H.H. Hellmer, J.N. Schwarz and T. Busche. 2005. On iceberg behaviour: observations, model results and satellite data. FRISP Report 16, 19-25.

Thyssen, F., A. Bombosch and H. Sandhäger. 1993. Elevation, ice thickness and structure mark maps of the central part of the Filchner-Ronne Ice Shelf. Polarforschung, 62(1), 17-26.

Vaughan, D.G. 1993. Relating the occurrence of crevasses to surface strain rates. J. Glaciol., 39(132), 255-266.

Vaughan, D.G., J.L. Bamber, M.B. Giovinetto, J. Russell and A.P.R. Cooper. 1999. Reassessment of net surface mass balance in Antarctica. J. Climate, 12(4), 933-946.

Weertman, J. 1957. Deformation of floating ice shelves. J. Glaciol., 3(21), 38-42. 